\title{
Evaluación del compost de guano de pollo en el rendimiento y calidad nutricional de la alfalfa en la sierra central del Perú
}

\author{
Evaluation of chicken manure compost in the yield and nutritional quality \\ of alfalfa in the central highlands of Peru
}

Jorge Castro Bedriñana ${ }^{1,2}$, Doris Chirinos Peinado ${ }^{1}$, Percy Lara Schwartz ${ }^{1}$

\section{Resumen}

Se evaluó el efecto del uso de compost de guano de pollos (CGP) en niveles de (T1) 0, (T2) 10 y (T3) $20 \mathrm{t} /$ ha sobre el rendimiento de forraje verde (FV), materia seca (MS), altura de planta (AP) y proteína total (PT) de la alfalfa en una pradera de Huancayo (Junín, Perú). El abonamiento se hizo al primer día del estudio y al inicio de la semana 6. El primer corte se hizo a los 42 días del primer abonamiento y el segundo corte a los 35 días del segundo abonamiento. Los rendimientos al segundo corte de FV en T1, T2 y T3 fueron de 18.6, 23.5 y 26.8 t/ha $(\mathrm{p}<0.05)$, de MS de 2.5, 7.0 y $7.1 \mathrm{t} / \mathrm{ha}(\mathrm{p}<0.05)$, de PT de 0.8, 1.0 y $1.2 \mathrm{t} / \mathrm{ha}(\mathrm{p}<0.05)$ y de AP de $60.8,66.9$ y $63.8 \mathrm{~cm}$, respectivamente $(\mathrm{p}<0.05)$. Se demuestra que es posible emplear compost de guano de pollos broiler para obtener una mayor producción orgánica de alfalfa.

Palabras clave: compost; alfalfa; proteína total; guano de pollos; altura de planta

\section{Abstract}

The effect of using chicken manure compost (CGP) at levels of (T1) 0, (T2) 10 and (T3) $20 \mathrm{t} / \mathrm{ha}$, on green forage yield (GF), dry matter (DM), plant height (PH) and total protein (TP) of alfalfa, in a pasture area of Huancayo (Junín, Peru) was evaluated. The fertilization was done on the first day of the study and at the beginning of week 6 . The first cut was done at 42 days of the first fertilization and the second at 35 days of the second fertilization. The yields at the second cut of GF in T1, T2 and T3 were 18.6, 23.5

\footnotetext{
${ }^{1}$ Facultad de Zootecnia, Universidad Nacional del Centro del Perú, Huancayo, Perú

${ }^{2}$ E-mail: jorgecastrobe@yahoo.com
}

Recibido: 23 de enero de 2019

Aceptado para publicación: 20 de octubre de 2019 
and 26.8 t/ha $(\mathrm{p}<0.05)$, of DM were 2.5, 7.0 and 7.1 t/ha $(\mathrm{p}<0.05)$, of TP were $0.8,1.0$ and 1.2 $\mathrm{t} / \mathrm{ha}(\mathrm{p}<0.05)$ and of PH were $60.8,66.9$ and $63.8 \mathrm{~cm}$, respectively $(\mathrm{p}<0.05)$. It was shown that it is possible to use broiler chicken manure compost to obtain an improved organic alfalfa production.

Key words: compost; alfalfa; total protein; chicken manure; plant height

\section{INTRODUCCIÓN}

La alfalfa (Medicago sativa $\mathrm{L}$ ) es catalogada como uno de los forrajes más importantes para la alimentación del ganado (Bouton, 2001; Martin et al., 2006), siéndolo también para la producción de cuyes y conejos, tanto por la cantidad de forraje obtenido por superficie cultivada, como por su valor nutritivo (Bazán et al., 2017).

La alfalfa, por su alto rendimiento y contenido de proteína, vitaminas, minerales (especialmente calcio) y bajo porcentaje de fibra, es excelente para la producción de leche; además ayuda a enriquecer el suelo por su capacidad de fijar nitrógeno atmosférico en asociación con bacterias del género Rhizobium(Bouton, 2001).

Puesto que el rendimiento y calidad nutricional del forraje define, en gran parte, la respuesta animal, el suelo debe tener una adecuada incorporación de materia orgánica $\mathrm{y}$ de nutrientes que permitan un proceso de producción eficiente. Para ello, tradicionalmente se ha empleado la fertilización química que aporta principalmente nitrógeno, fósforo y potasio, la cual, tiene un efecto a corto plazo (Cueto et al., 2003) y puede afectar las características fisicoquímicas y microbiológicas de suelo; ya que el uso excesivo incrementa los procesos degradativos por la disminución de la fracción orgánica y desequilibra el ciclo global del nitrógeno y del fósforo (Laurin et al., 2006). El uso de fertilizantes químicos es costoso (Powell et al., 2004) y no es una tecnología ecológica ni sostenible. Este tipo de fertilización debe ser gra- dualmente complementado o sustituido por sistemas de producción orgánica, dirigidos a obtener una biomasa de calidad, con la ventaja de mejorar la calidad física, química y biológica de los suelos (Ekinki et al., 2004; Martin et al., 2006; Gordillo et al., 2011).

Una opción al empleo de fertilizantes químicos podría ser el uso o transformación de los residuos del sector avícola, principalmente el guano de aves de postura y la cama de los pollos parrilleros, los cuales están compuestos por heces, orines, desperdicios de alimento y el material de la cama; que al ser desperdiciados o mal eliminados generan un impacto negativo en el ambiente, incluyendo problemas de salud pública (Ko et al., 2008). La estabilización aeróbica del estiércol de aves, a través del compostaje es una alternativa de tratamiento para obtener un abono de calidad y reducir la contaminación (RuizFigueroa, 2009; Riera et al., 2014). Se tienen reportes que indican que la aplicación anual de compost y estiércol de bovino en alfalfares (Martin et al., 2006) y de compostas generadas a partir de basura orgánica municipal y residuos de cultivos, permiten obtener suelos de mejor calidad y producciones de alfalfa similares a las obtenidas con fertilizante inorgánico (Herencia et al., 2007; Lestingi et al., 2009).

El compost de guano de pollo (CGP), obtenido a partir de la descomposición controlada del guano de pollos broilers, puede ser empleado para la producción de forraje orgánico, mejorando su calidad y la del suelo. Este procesamiento se realiza en condiciones aeróbicas, evitando la emisión de $\mathrm{CO}_{2}$, amoniaco y otros compuestos volátiles a la 
atmósfera. Tiene entre 20 y $30 \%$ de humedad, $\mathrm{pH}$ de 7.0-8.5, materia orgánica $23.8 \%$, nitrógeno $1.10 \%, \mathrm{P}_{2} \mathrm{O}_{5} 1.9 \%, \mathrm{~K}_{2} \mathrm{O} 3.4 \%$, $\mathrm{CaO} 5.1 \%, \mathrm{MgO} 1,5 \%$, Na $0.6 \%$, boro 61 ppm, Cu 48 ppm, Zn 285 ppm, Mn 565 ppm y Fe 13005 ppm. Además, es libre de Pseudomonas, Salmonella y bacterias fecales.

Ante la existencia de este producto y la necesidad de mejorar el rendimiento y calidad nutricional de la alfalfa, el objetivo del estudio fue determinar la altura de planta y el rendimiento de biomasa, materia seca y proteína total de la alfalfa, incorporando 0,10 y 20 toneladas de CGP por hectárea. Asimismo, obtener un forraje orgánico, que permita promover la salud animal y humana, obteniendo productos de origen animal inocuos y seguros.

\section{Materiales y MéTOdos}

La investigación se realizó en un potrero de alfalfa de la variedad Aragón de dos años y de una extensión de $1250 \mathrm{~m}^{2}$, ubicado en el distrito de El Tambo, provincia de Huancayo, Perú, a una altitud de $3250 \mathrm{msnm}$. El experimento tuvo una duración de 11 semanas. Se utilizaron tres parcelas de alfalfa, de una extensión total de $480 \mathrm{~m}^{2}$, divida en tres subparcelas de $160 \mathrm{~m}^{2}$. La primera parcela fue considerada Testigo (T1: sin fertilización o abonamiento y las otras dos fueron abonadas con GCP (T2: 10 t/ha; T3: 20 t/ha). Se realizaron dos abonamientos, el primero al inicio del experimento y el segundo al finalizar la sexta semana, luego del primer corte. Además, se hizo un segundo corte a las cinco semanas del segundo abonamiento.

Se evaluó el rendimiento de forraje verde, materia seca, proteína y altura de planta. En cada evaluación se tomaron cuatro muestras de $1 \mathrm{~m}^{2}$ por parcela a una altura de corte de $5 \mathrm{~cm}$ (Ferret, 2003). Se retiraron las malezas y se registró el peso. Luego se tomaron muestras de $100 \mathrm{~g}$ (peso fresco) y se seca- ron en una estufa a $65{ }^{\circ} \mathrm{C}$ durante 72 horas. Estas muestras fueron pesadas y por diferencia de peso se obtuvo el porcentaje de materia seca. Para evaluar la altura de planta, antes de cada corte, con un flexómetro se midieron 10 plantas al azar por muestra por parcela, desde el nivel del suelo hasta la última hoja del tallo.

El contenido de materia seca (MS) y proteína total (PT) de las muestras de alfalfa fueron determinados en el laboratorio de nutrición animal de la Facultad de Zootecnia de la Universidad Nacional del Centro del Perú, siguiendo la metodología del análisis proximal descrito por la AOAC (1990).

Se realizaron análisis de varianza para las variables respuesta con tres tratamientos y cuatro repeticiones por tratamiento. Las diferencias entre promedios se analizaron con pruebas de significación Duncan con un $\mathrm{p}<0.05$, empleando el SPSS v. 16.

\section{Resultados y Discusión}

La incorporación del compost de guano de pollo (CGP) en niveles de 10 y $20 \mathrm{t} / \mathrm{ha}$ afectaron en forma significativa los parámetros productivos de la alfalfa en ambos cortes realizados a los 42 y 35 días del primer y segundo abonamiento, respectivamente (Cuadro 1).

\section{Rendimiento de Forraje Verde}

El rendimiento de FV a los 42 días del primer abonamiento con CGP no fue estadísticamente diferente; sin embargo, en el segundo corte se logra observar mejores rendimientos con el empleo del CGP (Cuadro $1 ; \mathrm{p}<0.05$ ). Diversos estudios empleando enmiendas orgánicas reportan un efecto positivo en la disponibilidad de fósforo después de 90 días de su aplicación (Hernández et al., 2006; Aguirre et al., 2007), debido a que el fósforo orgánico tiene que ser liberado por mineralización para que las plantas puedan 
Cuadro 1 Parámetros productivos de alfalfa con abonamiento con dos niveles de guano de compost de pollos broiler (CGP)

\begin{tabular}{lcccccc}
\hline & \multicolumn{3}{c}{ Primer corte } & \multicolumn{3}{c}{ Segundo corte } \\
\cline { 2 - 7 } Parámetro & $\mathrm{T} 1$ & $\mathrm{~T} 2$ & $\mathrm{~T} 3$ & $\mathrm{~T} 1$ & $\mathrm{~T} 2$ & $\mathrm{~T} 3$ \\
& $0 \mathrm{t} / \mathrm{ha}$ & $10 \mathrm{t} / \mathrm{ha}$ & $20 \mathrm{t} / \mathrm{ha}$ & $0 \mathrm{t} / \mathrm{ha}$ & $10 \mathrm{t} / \mathrm{ha}$ & $20 \mathrm{t} / \mathrm{ha}$ \\
& $\mathrm{CGP}$ & $\mathrm{CGP}$ & CGP & CGP & CGP & CGP \\
\hline Forraje verde, $\mathrm{kg} / \mathrm{m}^{2}$ & $3.00^{\mathrm{a}}$ & $3.34^{\mathrm{a}}$ & $3.25^{\mathrm{a}}$ & $1.87^{\mathrm{b}}$ & $2.35^{\mathrm{a}}$ & $2.68^{\mathrm{a}}$ \\
Materia seca, $\mathrm{kg} / \mathrm{m}^{2}$ & $0.46^{\mathrm{b}}$ & $1.00^{\mathrm{a}}$ & $0.94^{\mathrm{a}}$ & $0.25^{\mathrm{b}}$ & $0.895^{\mathrm{a}}$ & $0.71^{\mathrm{a}}$ \\
Proteína total, $\mathrm{kg} / \mathrm{m}^{2}$ & $0.13^{\mathrm{a}}$ & $0.143^{\mathrm{a}}$ & $0.15^{\mathrm{a}}$ & $0.08^{\mathrm{c}}$ & $0.101^{\mathrm{b}}$ & $0.12^{\mathrm{a}}$ \\
Altura de planta, cm & $61.41^{\mathrm{b}}$ & $72.35^{\mathrm{a}}$ & $70.34^{\mathrm{a}}$ & $60.84^{\mathrm{c}}$ & $66.86^{\mathrm{a}}$ & $63.76^{\mathrm{b}}$ \\
\hline
\end{tabular}

$a, b, c$ Valores en filas con letras diferentes son significativamente diferentes $(p<0.05)$

Los cortes se hicieron en el día 42 y día 77 del estudio

absorberlo. La fertilización es más efectiva cuando se realizan varias aplicaciones en comparación a una sola al inicio del cultivo (Figueroa et al., 2010). Similarmente, el nitrógeno que se encuentra mayormente en forma orgánica (más del 95\%), ligado al ciclo de la materia orgánica, debe evolucionar hasta nitratos, que aportan nitrógeno disponible para las plantas en el corto plazo (Hernández et al., 2006; Aguirre et al., 2007).

El rendimiento de $\mathrm{FV} / \mathrm{m}^{2}$ por tratamiento, en el segundo corte, luego de 35 días de realizado el primer corte fue significativamente mayor en T3 y T2 con relación a $\mathrm{T} 1$ ( $<<0.05$; Cuadro 1). Se evidencia que el CGP aporta materia orgánica y nutrientes al suelo que son utilizados por la alfalfa, mejorando su tasa de crecimiento; resultado que está en línea con otros estudio que indican que el rendimiento de alfalfa verde fue mejorado por el uso de compost y/o abono orgánico (Diaz, 2017; Martel, 2018), compost a base de residuos sólidos municipales (Herencia et al., 2007; Lestingi et al., 2009), compost de estiércol de vaca y aves de corral (Daur, 2016), estiércol de ovino combinado con superfosfato triple (Flores-Aguilar et al., 2012), estiércol de porcino (Lloveras et al.,
2017), estiércol de bovino (Salazar et al., 2010), fertilizante orgánico e inorgánico (Hernández et al., 2006; Vázquez et al., 2010); resultados que derivan del incremento en materia orgánica (Salazar et al., 2010; Hernández et al., 2006), de fósforo (Jiménez et al., 2004; Aguirre et al., 2007) y de elevar el $\mathrm{pH}$ lográndose una mayor tasa de mineralización del $\mathrm{P}$, permitiendo una mayor solubilidad y aprovechamiento de este nutriente (Duran et al., 2006; Flores-Aguilar et al., 2012).

Es importante resaltar la calidad del CGP en comparación a compost a base de estiércoles de otras especies, porque el estiércol de broilers es alto en productos nitrogenados. Castro y Chirinos (2008) indican que las dietas de inicio y acabado de los pollos tiene 22.5 y $19.5 \%$ de proteína total, mientras que las dietas de los vacunos tienen entre 12 y $16 \%$ de proteína. El CGP aporta varios minerales, incrementando la disponibilidad de estos nutrientes para la planta, aunado al incremento de la retención de humedad. Se informa que los fertilizantes orgánicos suministran entre 2 y $4 \mathrm{~g} / \mathrm{kg}$ de fósforo (Eghball, 2002), cantidad adecuada de fósforo requerido por la alfalfa (Gaskell et al., 2006). 


\section{Rendimiento de Materia Seca}

El porcentaje de MS de la alfalfa al primer corte (28.43-30.11\%) estuvo muy próximo al valor de $20-28 \%$ reportado por Zabala (1995), dependiendo de la época del año y de la edad de la planta, aunque inferior al 21$24 \%$ señalado por Fernández (2010). Así mismo, Castro y Chirinos (2008) mencionan que la alfalfa en prefloración, en inicio de floración y en plena floración tiene 21.1, $25.5 \mathrm{y}$ $25.0 \%$ de MS, respectivamente. Los rendimientos de MS fueron prácticamente duplicados por la incorporación de CGP $(\mathrm{p}<0.05)$.

Al segundo corte, el contenido de MS estuvo entre 24.01 y $29.57 \%$, valor similar a lo reportado por otros autores (Castro y Chirinos, 2008; Fernández, 2010) y mayores a los reportados por Bazán et al. (2017) en Huaral, Perú. El rendimiento de $\mathrm{MS} / \mathrm{m}^{2}$ fue 3.6 y 2.7 veces más alto cuando se utilizó el CGP en 10 y $20 \mathrm{t} / \mathrm{ha}$ con relación al testigo T1. Este resultado guarda relación con varios estudios que reportan un incremento de MS de la alfalfa por el uso de fertilización orgánica (Lloveras et al., 2004; Vázquez et al., 2010; Flores-Aguilar et al., 2012; Daur, 2016; Díaz, 2017; Martel, 2018).

\section{Rendimiento de Proteína Total}

El contenido de PT $(\mathrm{Nx} 6.25)$ al primer corte, en base seca, estuvo entre $14.2 \mathrm{y}$ $15.5 \%$, equivalente al contenido en base fresca de 4.28-4.50\%; rango que se encuentra dentro del $4.32 \%$ indicado por Castro y Chirinos (2008) para la alfalfa en prefloración. Al segundo corte, el contenido porcentual de PT fue de 15.9-17.7\% en base seca y de 4.25$4.70 \%$ en base fresca (Cuadro 1). Igualmente, similares a los reportados por Castro y Chirinos (2008) de 3.11-4.32\% de PT. Por otro lado, Martel (2018) reportó valores superiores a $6 \%$ de $\mathrm{PT}$ en base fresca en alfalfares de Huánuco, Perú, a los que se les aplicó abono orgánico cada 14 días más compost en una cantidad de $4 \mathrm{t} / \mathrm{ha}$.
El rendimiento de $\mathrm{PT}$ en el primer corte a los 42 días se incrementó en 15 y $19 \mathrm{~g} / \mathrm{m}^{2}$ $(\mathrm{p}>0.05)$ al incorporar CGP en T2 y T3, respectivamente, con respecto al grupo testigo (T1). En el segundo corte, 35 días después del primer corte y segundo abonamiento, el incremento de PT fue de 21 y $40 \mathrm{~g} / \mathrm{m}^{2}$ $(\mathrm{p}<0.05)$, respectivamente, con respecto a $\mathrm{T} 1$. Este incremento en el rendimiento de PT de la alfalfa no solo tiene importancia nutricional sino económica, pues en la práctica puede permitir alimentar a un mayor número de animales y obtener una mejor respuesta animal.

\section{Altura de Planta}

A los 42 días del experimento, la altura de planta (AP) fue significativamente mejorada por el uso del abonamiento con CGP $(\mathrm{p}<0.05)$. La AP aumentó en 10.93 y 8.93 $\mathrm{cm}$ cuando se empleó el abonamiento con CGP en niveles de 10 y 20 t/ha. Al segundo corte, 35 días después del segundo abonamiento, la AP también fue mejorada por la incorporación del CGP $(\mathrm{p}<0.05)$, aunque en menor grado, registrándose la mayor AP al utilizar $10 \mathrm{t} /$ ha de CGP (Cuadro 1).

La AP determinada en este estudio está dentro del rango reportado en Cajamarca, Perú, de 62 a $85 \mathrm{~cm}$ con el uso de abono orgánico (Díaz, 2017), y otro con 14 variedades de alfalfa en México con AP entre 59.2 y $68.9 \mathrm{~cm}$ (Morales et al., 2006).

La AP es un importante indicador indirecto de la calidad de los forrajes, pues no solo las hojas son más grandes, sino que además se incrementa la relación hoja:tallo (Villegas et al., 2004). Así mismo, en las hojas se encuentra el mayor contenido de proteína digestible para el ganado (Bouton, 2001; Villegas et al., 2004). Adicionalmente, puesto que el vigor de un pasto está estrechamente ligado a la AP, se puede decir que el vigor de la alfalfa en el presente estudio fue mejorado por efecto del CGP. 


\section{ConClusiones}

El rendimiento de forraje verde, materia seca, proteína total y altura de la alfalfa fueron significativamente mejorados $(\mathrm{p}<0.05)$ al utilizar compost de guano de pollo en niveles de 10 y $20 \mathrm{t} / \mathrm{ha}$.

\section{Literatura Citada}

1. Aguirre ME, Bussetti SG, Santa María RM. 2007. Fósforo hidrosoluble y disponible en el suelo por el agregado de cáscara de girasol. Rev Inv Fac Cienc Agraria 11: 1-6.

2. $A O A C$. 1990. Official methods of analysis of the Association of Official Analytical Chemists. Vol $1.15^{\text {th }}$ ed. Washington DC: AOAC. 1298 p.

3. Bazán V, Yamada G, Coronado L, Fuentes N. 2017. Comportamiento productivo de la alfalfa (Medicago sativa) de la variedad Caravelí sometida al pastoreo en el valle de Huaral. Rev Inv Vet Perú 28: 743-749. doi: 10.15381/ rivep.v28i3.13359

4. Bouton JH. 2001. Alfalfa. En: XIX International Grassland Congress. Sao Pablo, Brasil.

5. Castro J, Chirinos D. 2008. Manual de formulación de raciones balanceadas para animales. Lima: CONCYTEC. $230 \mathrm{p}$.

6. Cueto WJ, Quiroga GH, Becerra MC. 2003. Nitrógeno disponible y desarrollo del ballico anual. 1. Producción, calidad del forraje y acumulación de nitratos. Terra 21:285-295.

7. Daur I. 2016. Organic alfalfa production using different EM.1 composts. Turk J Field Crops 21: 139147. doi: $10.17557 / \mathrm{tjfc} .23036$

8. Díaz S. 2017. Elaboración de abono orgánico (biol) para su utilización en la producción de alfalfa (Medicago sativa $\mathrm{v}$. vicus) en Cajamarca. Tesis de Ingeniero Ambiental y Prevención de Riesgos.
Cajamarca, Perú: Univ. Privada Antonio Guillermo Urrelo. $85 \mathrm{p}$.

9. Eghball, B. 2002. Soil properties as influenced by phosphorus- and nitrogenbased manure and compost applications. Agron J 94: 128-135. doi: 10.2134/ agronj2002.0128

10. Ekinki K, Keener H, Elwell D. 2004. Effects of aeration strategies on the composting process: part 1. Experimental studies. Trans ASAE 47: 1697-1708. doi: 10.13031/2013.17612

11. Fernández H. 2010. Tabla de composición de alimentos para rumiantes. Nutrición Animal. Argentina: INTA EEA Balcarce.

12. Ferret A. 2003. Control de calidad de forrajes. En: XIX Curso de Especialización FEDNA. Madrid. [Internet]. Disponible en: http://fundacionfedna.org/ sites/default/files/03CAP_VII.pdf

13. Figueroa-Viramontes $U$, Cueto-Wong JA, Delgado JA, Núñez-Hernández G, Reta-Sánchez DG, Quiroga-Garza HM, Faz-Contreras R, et al. 2010. Estiércol de bovino lechero sobre el rendimiento y recuperación aparente de nitrógeno en maíz forrajero. Terra Latinoam 8: 361-369.

14. Flores-Aguilar J, Vázquez-Rosales $R$, Solano-Vergara J, Aguirre-Flores V, Flores-Pérez, F, Bahena-Galindo $M$, Oliver-Guadarrama R, et al. 2012. Efecto de fertilizante orgánico, inorgánico y su combinación en la producción de alfalfa y propiedades químicas del suelo. Terra Latinoam 30: 213-220

15. Gaskell M, Smith R, Mitchell J, Kuike ST, Fouche C, Hartz T, Horwath W, et al. 2006. Soil fertility management for organic crops. USA: University of California. Pub. 7249. 8 p.

16. Gordillo F, Peralta E, Chávez E, Contreras V, Campuzano A, Ruiz $O$. 2011. Producción y evaluación del proceso de compostaje a partir de desechos agroindustriales de Saccharum officinarum (caña de azúcar). Rev Inv Agropec 37: 140-149. 
17. Ko HJ, Kim KY, Kim HT, Kim CN, Umeda M. 2008. Evaluation of maturity parameters and heavy metal contents in compost made from animal manure. Waste Manag 28: 813-820. doi: 10.1016/ j.wasman.2007.05.010

18. Herencia JF, Ruiz PJ, Melero PS, García Galvis A, Morillo E, Maqueda C. 2007. Comparison between organic and mineral fertilization for soil fertility levels, crop macronutrient concentrations and yield. Agron J 99: 973-983. doi: 10.2134/agronj2006.0168

19. Hernández MT, Chocano C, Melgares $J$, González D, García C. 2006. Incidencia de enmiendas orgánicas sobre la calidad del suelo en ciruelo ecológico. En: VII Congreso SEAE. Zaragoza, España.

20. Jiménez, L, Larreal M, Noguera $N$. 2004. Efectos del estiércol de bovino sobre algunas propiedades químicas de un untisol degradado en el área de la Machiques Colón, estado de Zulia. Rev Fac Agron 21: 311-321.

21. Laurin M, Llosá MJ, Gonzálvez V, Porcuna JL. 2006. El papel de la agricultura ecológica en la disminución del uso de fertilizantes y productos fitosanitarios químicos. En: VII Congreso SEAE, Zaragoza.

22. Lestingi A, Bovera F, Piccolo V, Convertini G, Montemurro F. 2009. Effects of compost organic amendments on chemical composition and in vitro digestibility of alfalfa (Medicago sativa L). Ital J Anim Sci 8: 201-209. doi: 10.4081/ijas.2009.201

23. Lloveras J, Arán M, Villar P, Ballesta A, Arcaya A, Vilanova X, Delgado I, et al. 2004. Effect of swine slurry on alfalfa production and on tissue and soil nutrient concentration. Agron J 96: 986991. doi: 10.2134/agronj2004.0986

24. Martel L. 2018. Efecto de los niveles de abonos foliares en el rendimiento y calidad de cultivo de Alfalfa establecida (Medicago sativa $\mathrm{L}$ ), en condiciones edafoclimáticas de Yacupunta-Huánuco-2017. Tesis de Ingeniero Agrónomo. Huá-nuco, Perú: Univ. Nacional H. Valdizán. 68 p.
25. Martin EC, Slack DC, Tanksley KA, Basso B. 2006. Effects of fresh and composted dairy manure applications on alfalfa yield and the environment in Arizona. Agron J 98: 80-84. doi: 10.2134/ agronj2005.0039

26. Morales AJ, Jiménez VJ, Velasco VA, Villegas AY, Enríquez Del Valle JR, Hernández GA. 2006. Evaluación de 14 variedades de alfalfa con fertirriego en la Mixteca de Oaxaca. Tec Pecu Mex 44: 277-288.

27. Powell JM, Wu Z, Kelling K, Cusick P, Muñoz G 2004. Differential nitrogen15 labeling of dairy manure components for nitrogen cycling studies. Agron J 96: 433-441. doi: 10.2134/agronj2004.0433

28. Riera NI, Della-Torre V, Rizzo PF, Butti M, Bressan FM, Zárate N, Weigandt C, et al. 2014. Evaluación del proceso de compostaje de dos mezclas de residuos avícolas Rev Fac Cienc Agrar 46: 195-203.

29. Ruiz-Figueroa JF. 2009. Ingeniería del compostaje. México: Univ. Autónoma Chapingo. $237 \mathrm{p}$.

30. Salazar-Sosa E, Trejo-Escareño HI, López-Martínez JD, Vázquez-Vásquez C, Serrato-Corona S, Orona-Castillo I, Flores-Márgez JP. 2010. Efecto residual de estiércol bovino sobre el rendimiento de maíz forrajero y propiedades del suelo. Terra Latinoam 28: 381-390.

31. Vázquez C, García JL, Salazar E, Murillo B, Orona I, Zúñiga R, Rueda $E O$, et al. 2010. Rendimiento y valor nutritivo de forraje de alfalfa (Medicago sativa $\mathrm{L}$ ) con diferentes dosis de estiércol bovino. Rev Mex Cienc Pecu 1: 363-372.

32. Villegas AY, Hernández GA, Pérez PJ, López CC, Herrera HJG, Enríquez QJF. 2004. Patrones estacionales de crecimiento de dos variedades de alfalfa (Medicago sativa L). Tec Pecu Mex 42: 145-158.

33. Zabala R. 1995. Producción de forraje bajo corte de cultivares de alfalfa sin reposo invernal en condiciones de riego en el valle inferior del Río Negro. Rev Arg Prod Anim 15: 266-268. 